14 timing of the cleansing either by apple or brushing. Most damage occurs if food debris is left undisturbed on the teeth for a long time, for example, during sleep; cleaning before sleep is most important. Ideally it should be done after every meal but failing that, the last thing before sleep. Bubble-and-swallow methods of mouth cleansing can be used after meals. Provided the method is started before the second deciduous molar erupts, food debris can be kept to a minimum on the distal surface of the first deciduous molar. If food debris collects behind the first deciduous molar, caries may commence in the distal surface of that tooth before the second molar has erupted and will spread to the mesial surface of the second molar as it erupts. [...]

Thus, the deciduous teeth are kept clean by chewing and rinsing measures which the child can carry out itself. Brushing to remove the apple from gums and teeth encourages the habit of the brush but is of minor value in cleaning the teeth of infants.

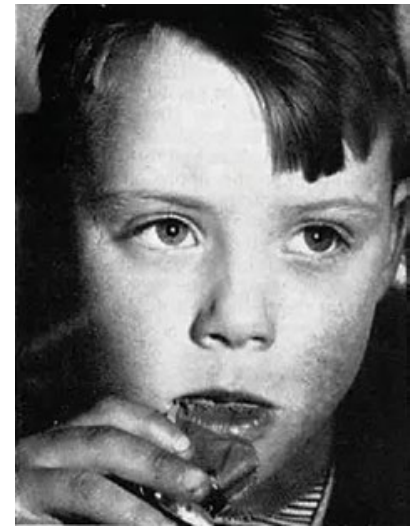

Fig. 2 Boy eating chocolate biscuit

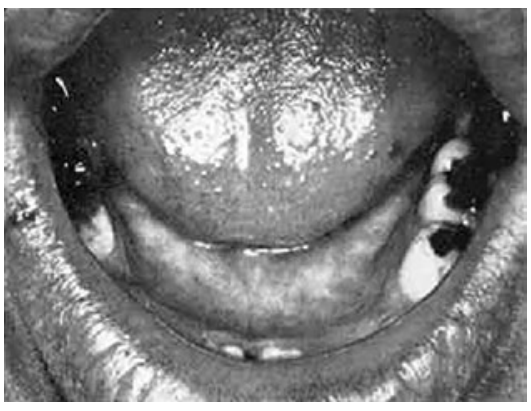

Fig. 4 Appearance of teeth of boy in Figure 2

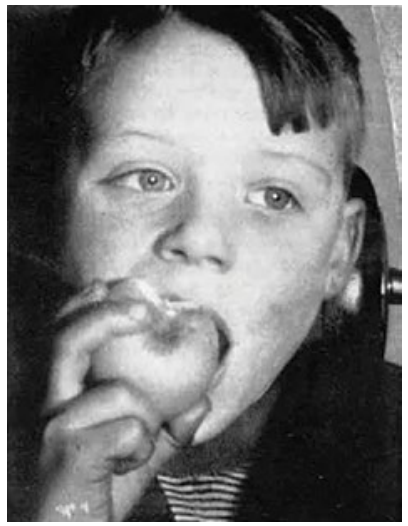

Fig. 3 Same boy with apple

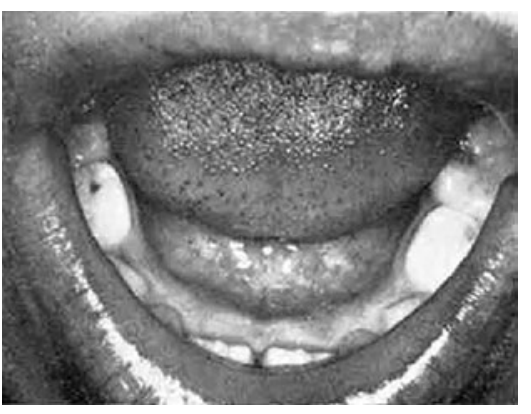

Fig. 5 Appearance of teeth after the chewing of one bite of apple following Figure 3

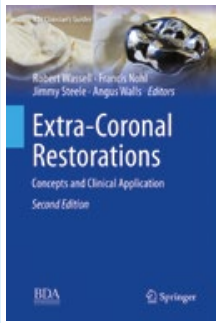

\section{EXTRA-CORONAL RESTORATIONS: CONCEPTS AND CLINICAL APPLICATION, SECOND EDITION}

Robert Wassell, Francis Nohl, Jimmy Steele, Angus Walls

2019; Springer;

price f139.99; pp. 463

ISBN: 9783319790923

I enjoyed reading this book of over 450 pages, with its well-written detail and useful information, much of it sensible advice and good guidance. There are useful references in each chapter encouraging further reading and a deeper understanding. The book covers a broad range of topics from clinical performance to managing risk, and also provides a look at immunological reactions and materials. Chapters on aesthetics, implant crowns and expected techniques for crowning teeth are also included.

This is a well-produced book with easy to follow text. There are a good number of diagrams and images and, despite the lack of clinical cases and a few unnecessary images, these supplement the text well.

The first third of the book provides an overview of the basics of general dentistry including short summaries of caries, endodontics, periodontal disease (using the old classification) and tooth wear. Unfortunately, the three pages dedicated to 'What is TSL' is possibly too brief to be of much value. This first part of the book is not particularly relevant to extra-coronal restorations but it is a good overview of many interesting topics in clinical dentistry which could be seen as additional content rather than irrelevant to the topic suggested by the title of the book. If the first third does frustrate some perhaps more experienced clinicians, then I suggest they go straight to the chapter on occlusal control, which is a gem. This chapter repeats one of the authors' excellent previously published table on seven ways to achieve occlusal space, now reduced to six ways.

Once the content gathers momentum beyond the 11 chapters, 'A healthy start' and 'Managing future risk', it takes off and this is where most clinicians will enjoy the detail. The latter chapters are particularly useful for those looking for techniques leading to a very good ending on retrofitting crowns to existing dentures. There is a good discussion outlining the benefits of provisional restorations, but some of the general restorative techniques such as impression recording is rather basic and not particularly up to date. There is, however, excellent advice on aspects such as the use of posts, cores and ferrules.

Given the title extra-coronal restorations, the book ends its journey a little prematurely as some newer and frequently discussed concepts such as vertical margins, BOPT (biologically-oriented preparation technique), contemporary core techniques, and the current options available through the application of digital dentistry are not given enough discussion.

This attractive book provides good and relevant information on much more than crowns and is available both as hardback and online, no doubt providing something for undergraduates and clinicians at all stages of their career.

Brian Millar 